\title{
0 sentido da vida para jovens dependentes químicos
}

\author{
The meaning of life for chemical dependent youngsters
}

Renata Lemos da Silva ${ }^{[a]}$, Felipe Schroeder de Oliveira ${ }^{[b]}$

\footnotetext{
[a] Graduanda do Curso de Psicologia do Centro Universitário Franciscano (Unifra), Santa Maria, RS - Brasil, e-mail: psicorenatinha@hotmail.com

${ }^{[b]}$ Mestre em Psicologia Social e da Personalidade pela Pontifícia Universidade Católica do Rio Grande do Sul (PUCRS), professor do Curso de Psicologia do Centro Universitário Franciscano (Unifra), Santa Maria, RS - Brasil, e-mail: schroeder.felipe@gmail.com
}

Recebido: 20/01/2011 Received: 01/20/2011

\section{Resumo}

O presente estudo trata do tema o sentido da vida para jovens dependentes químicos. O objetivo da pesquisa foi investigar a atribuição de sentido que os jovens dependentes químicos dão às suas vidas. Participaram da pesquisa três jovens com idade entre 19 e 27 anos que têm em comum a dependência química do crack e que estão internados em tratamento numa instituição de recuperação e inserção social de jovens e adultos. Para a coleta de dados foram utilizados uma entrevista individual semiestruturada e um grupo focal. Os dados foram analisados mediante o enfoque fenomenológico segundo Martins e Bicudo (1994). Os resultados apontaram pela busca de sentido na manifestação da fé e na crença em Deus que viria a ajudar na manutenção de uma vida futura livre das drogas. Demonstraram o desejo em poder trabalhar e constituir uma família, bem como o de manter a abstinência e a sobriedade. Considera-se que os participantes do estudo associam o sentido da vida às relações familiares, à fé, ao trabalho e ao seu comprometimento com o tratamento.

Palavras-chave: Sentido da vida. Jovens. Dependência química.

\begin{abstract}
The present study talks about the meaning of life for chemical dependent youngsters. The purpose of the research was to investigate the meaning that the chemical dependent youngsters attribute to their lives. The research was made with three youngsters with ages between 19 and 27 years old, who have in common the chemical dependence for crack and who are hospitalized in treatment institutions for recovery and social insertion for youths and adults. A half-structured individual interview and a focal group were used for the data collection. The data were analyzed through a phenomenological focus, according to Martins and Bicudo (1994). The results appointed the search for meaning by faith manifestation and in the belief of God which would come to help in the maintenance of a future life free from drugs. They demonstrated the desire of being able to work and constitute a family, as well as keeping themselves sober and abstinent. It is considered that the participants of the study associate the meaning of life to family relations, faith, labor and to their commitment to the treatment.
\end{abstract}

Keywords: Meaning of life. Youngsters. Chemical dependence. 


\section{Introdução}

O sentido da vida, para Viktor Emil Frankl, precisa ser encontrado e descoberto pela própria pessoa, sendo a consciência a orientadora nessa busca pelo sentido. 0 homem busca sempre o significado para sua vida, movendo-se em prol de um sentido para viver, considerado como "vontade de sentido" (Frankl, 2005).

Existem três formas de encontrar o sentido da vida. A primeira forma seria a partir dos valores de criação, que são encontrados na ação realizada pela pessoa, enquanto criadora e enriquecedora de suas atividades. Outra forma de encontrar sentido é pela entrega à experiência de algo que se recebe do mundo ou no encontro de amor com outra pessoa, sendo considerados os valores de vivência. Caso haja a impossibilidade da criação ou do amor, pode-se encontrar o sentido da experiência de um destino imutável, pela escolha de uma atitude afirmativa da vida, fazendo surgir os valores de atitude (Pereira, 2008).

Segundo Aquino et al. (2009), a falta de sentido é a raiz do vazio existencial do homem ocidental atual, pois este busca uma vida de prazer ou êxito, esquecendo-se das metas transcendentes. 0 ser humano passa, então, a experienciar uma grande frustração, pois o que torna-se insuportável não é o sofrer, mas sim o viver sem um ideal. Na antiguidade, os homens buscavam na tradição um sentido à sua vida. Já na atualidade, existe uma dificuldade em acolher os valores que foram deixados ao longo da história.

Um tema debatido na atualidade e que pode representar essa situação do homem ocidental é um grave problema social e de saúde pública: a dependência química (Pratta \& Santos, 2009). De acordo com Frankl (2007), a população jovem, especialmente vulnerável ao apelo das drogas, vive a síndrome da neurose de massa gerada pela falta de sentido, constituído na tríade "dependência de drogas, agressão e depressão." 0 consumo de drogas é parte do fenômeno da falta de sentido, que resulta numa frustração das necessidades existenciais, tendo sido visto como um fenômeno universal (Frankl, 1991).

\section{A dependência química}

O Manual Diagnóstico e Estatístico de Transtornos Mentais, DSM IV-TR (2002), traz os seguintes critérios para o diagnóstico de dependência de substâncias, que, por sua vez, devem ocorrer a qualquer momento no mesmo período de 12 meses:

1) Tolerância, definida por qualquer um dos seguintes aspectos:

- necessidade de quantidades progressivamente maiores da substância para adquirir a intoxicação ou efeito desejado;

- acentuada redução do efeito com o uso continuado da mesma quantidade de substância.

2) Abstinência, manifestada por qualquer dos seguintes aspectos:

- síndrome de abstinência característica para a substância (consultar os Critérios A e B dos conjuntos de critérios para abstinência das substâncias específicas);

- a mesma substância (ou uma substância estreitamente relacionada) é consumida para aliviar ou evitar sintomas de abstinência.

3) A substância é frequentemente consumida em maiores quantidades ou por um período mais longo do que o pretendido.

4) Existe um desejo persistente ou esforços mal-sucedidos no sentido de reduzir ou controlar o uso da substância.

5) Muito tempo é gasto em atividades necessárias para a obtenção da substância (por ex., consultas a múltiplos médicos ou fazer longas viagens de automóvel), na utilização da substância (por ex., fumar em grupo) ou na recuperação de seus efeitos.

6) Importantes atividades sociais, ocupacionais ou recreativas são abandonadas ou reduzidas em virtude do uso da substância.

7) 0 uso da substância contínua, apesar da consciência de ter um problema físico ou psicológico persistente ou recorrente que tende a ser causado ou exacerbado pela substância (por ex., uso atual de cocaína, embora o indivíduo reconheça que sua depressão é induzida por ela, ou consumo continuado de bebidas alcoólicas, embora o indivíduo reconheça que uma úlcera piorou pelo consumo do álcool).

De acordo com o II Levantamento domiciliar sobre o uso de drogas psicotrópicas no Brasil, envolvendo as 108 maiores cidades do país, realizado por Carlini et al. (2006) na Região Sul, o álcool e o tabaco são as drogas mais utilizadas, seguidas pela 
maconha. Nas Regiões Sul e Sudeste, os entrevistados dizem ter grande facilidade em encontrar cocaína e crack, o que coincide com os índices de maior prevalência para essas drogas nessas regiões.

De acordo com o V Levantamento Nacional sobre o consumo de drogas psicotrópicas entre estudantes do ensino médio da rede pública de ensino, realizado por Carlini, Galduróz, Noto e Fonseca (2004) nas 27 capitais, o uso de solventes ficou em primeiro lugar no Brasil, com 15,4\%; o uso de maconha foi de 5,9\%; a cocaína teve uso de $2,0 \%$ dos estudantes, sendo que a tendência do uso de drogas na faixa etária superior a 18 anos de idade teve um aumento nas seguintes capitais: Belém, Brasília, Curitiba e Fortaleza. As drogas mais usadas pelos indivíduos do sexo masculino são: maconha, cocaína, energéticos e esteroides anabolizantes. Pelos do sexo feminino são os medicamentos: anfetamínicos e ansiolíticos.

Déa, Santos, Itakura e Olic (2004) trazem que o consumo das substâncias psicoativas serve para modificar o estado de consciência do usuário. Alguns dos motivos que levam a fazer uso podem ser gerados por curiosidade, desejo de transcendência, busca de prazer, sabedoria e imortalidade. Afirmam que o consumo excessivo das drogas é facilitado pelas dificuldades de relacionamento entre pais e filhos.

Guimarães, Santos, Freitas e Araujo (2008) descrevem a dependência química como um problema de saúde pública que tem desafiado os profissionais da saúde a compreenderem o perfil do usuário de substâncias psicoativas, pois há dificuldades no manejo e na abordagem do problema. $\mathrm{Na}$ atualidade, existe a necessidade de se estudar o perfil dos usuários de crack que acessam os serviços de saúde no Brasil.

Nassif Filho, Bettega, Lunedo, Maestri e Gortz (1999) descrevem que o crack é um subproduto da cocaína, muito mais potente e prejudicial que a cocaína inalada ou injetável. 0 uso do crack produz um efeito de euforia e profunda excitação. 0 início da ação começa por volta dos oito segundos, não passando de duas horas de euforia. Após esse período, o usuário entra num sono profundo.

0 uso de drogas pode causar dependência física ou psíquica. A primeira adapta e acostuma com que o organismo com a droga. Já na dependência psíqui$\mathrm{ca}$, as alterações comportamentais favorecem à iniciação e manutenção do vício, que se torna o centro da vida do usário (Rodrigues, 2000).

\section{Método}

Este trabalho enquadra-se no paradigma qualitativo e apresenta uma pesquisa de caráter exploratório (Bauer \& Gaskell, 2005).

Segundo Gil (2006), as pesquisas exploratórias têm como finalidade esclarecer, desenvolver e modificar conceitos e ideias, como a formulação de problemas precisos ou hipóteses de estudos posteriores. Acabam envolvendo levantamento bibliográfico e documental, entrevistas não padronizadas e estudos de caso.

\section{Participantes}

Os participantes foram três jovens do sexo masculino usuários de crack com idades entre 19 e 27 anos, internados numa instituição de recuperação e inserção social de jovens e adultos dependentes químicos, localizada na região central do Rio Grande do Sul.

Serão identificados como participante A (19 anos), 2 meses de internação; participante B (22 anos), oito meses e 15 dias e participante $\mathrm{C}$ ( 27 anos), oito meses de internação.

0 contato com os participantes foi mediado pela psicóloga do local, respeitados os procedimentos éticos para Pesquisas com Seres Humanos.

\section{Instrumentos para coleta de dados}

Os instrumentos utilizados para a realização deste projeto foram uma entrevista individual do tipo semiestruturada seguida de um grupo focal.

A entrevista semiestruturada, conforme Laville e Dionne (1999), consiste na formulação de perguntas abertas sem uma ordem preestabelecida. Os grupos focais, de acordo com Scarparo (2000), são importantes para que se percebam os sentimentos, interpretações e percepções de cada participante, havendo grande envolvimento dos mesmos deles.

\section{Análise dos dados}

Os dados foram analisados pelo enfoque fenomenológico. Esse tipo de método é composto por quatro momentos, segundo Martins e Bicudo (1994). 0 primeiro é do sentido do todo, em que o pesquisador deve compreender a linguagem do entrevistado. Na segunda etapa, aparece a discriminação das unidades de significado, quando se faz a divisão de 
unidades; logo após vem a transformação das expressões cotidianas do sujeito em uma linguagem psicológica. A última etapa é a síntese das unidades de significado transformadas em proposição.

\section{Resultados}

As questões identificadas em comum pelos participantes foram divididas, por sua vez, em cinco unidades de significados: sentido da vida; fé; recuperação; família e futuro.

Na questão do sentido da vida, verificou-se que os jovens em tratamento buscam um sentido e uma transformação para suas vidas, situação diferente de quando faziam o uso de drogas. Todos associam o sentido de sua vida aos seguintes pontos por eles relatados: seguir um caminho certo, do bem; ficar longe das drogas; buscar sua recuperação e conquistar seus sonhos.

Relataram a importância que hoje dão à dimensão espiritual de suas vidas, pois dizem buscar cada dia mais a presença de Deus como uma força que lhes traga alegria e que os ajude nos momentos difíceis.

A recuperação foi destacada como a maior meta de suas vidas atualmente. Manter-se sóbrio e em abstinência, "sempre se cuidando", aparece como um desafio constante. Um dos entrevistados destacou que "o importante é não olhar para trás, pois assim se evitará a recaída".

A família foi destacada como de extrema importância para todos eles. Os três citam a família como a base para tudo e que ela sempre esteve presente em meio às dificuldades. Relatam que hoje buscam a confiança e o amor dos familiares.

No futuro, todos pretendem realizar seus sonhos que já buscam desde hoje. Este sonho passa por ter uma família, trabalhar, se manter sóbrio e sentir-se feliz. Enxergam o tempo em que usavam drogas como um tempo perdido em suas vidas e que desejam recuperar. Fazer de suas vidas um exemplo para as outras pessoas, aparece como um projeto de vida em suas falas, como um sentido em suas vidas.

\section{Discussão dos resultados}

\section{Sentido da vida}

Na fala dos participantes, aparece a questão apontada por Frankl (1991), relacionando o sentido da vida ao trabalho e à prática de um ato, seja com a família ou com outras pessoas.

0 participante A traz: ... quero ser uma pessoa que trabalha, que vá pra casa; ter uma família. É isso que eu quero pra mim. 0 participante destaca que quer se dedicar ao trabalho e ter sua família. Essa intenção está atrelada ao sentido da vida, que por sua vez se estabelece na dedicação em prol de alguém e do empenho na execução do trabalho, pois ambos trazem realização ao sujeito.

0 entrevistado ainda trouxe que agora o cara é exemplo pros outros. Na rua o cara vai ser o exemplo pra toda vida, né? Na fala desse participante, o entrevistado coloca sua vida à disposição do outro, para passar algo a alguém em relação ao que passou com sua vida e servir de exemplo para outras pessoas. Assim como esse participante, o entrevistado $C$ ressalta a importância que para ele é fazer o que considera o bem a outras pessoas: importante esse lado também de fazer o bem, é poder ajudar outras pessoas que tenham o mesmo problema ...

De acordo com Pereira (2008), a pessoa não deve perguntar qual o sentido da vida numa postura reflexiva e autocêntrica. No entanto deve reconhecer que é a própria vida que está indagando sobre o sentido e somente a pessoa pode responder de maneira responsável por meio de suas ações.

0 participante $\mathrm{C}$ afirma ainda que hoje, na verdade, eu busco um sentido de vida, porque, desde os meus 14 anos, eu uso droga, não o crack em si, mas sempre usei muito álcool, então hoje é um recomeço de tudo... Os entrevistados relataram que, antes do tratamento, a vida não apresentava nenhum sentido. Para eles, tudo estava ligado às drogas e só começaram a se conscientizar da importância que a vida apresenta quando foram em busca do tratamento.

Conforme Gomes (1992), a logoterapia não é a busca "de um sentido", mas "do sentido", pois não basta inventar um sentido, devemos encontrar o sentido. Esse sentido é diferente do que se encontra nas ruas, porque nas ruas o sentido é diretivo e determinado pelo mundo. Porém o sentido que buscamos clama do interior de cada pessoa, por ser algo interno. Somente o homem seguindo a responsabilidade pela vida pode encontrá-lo. Esta responsabilidade é gerada pela liberdade de forma incondicional e está presente em sua consciência.

0 participante B trouxe que "nas ruas" não encontrava o sentido, mas agora vê a vida de outra maneira: sentido é ter uma mudança na vida, fiquei dois 
anos e meio nas ruas e não tinha sentido nenhum; agora que eu to vendo outro tipo de sentido. Outro jeito de viver. Esse participante destaca um dos pontos enfatizados pela logoterapia, de que o sentido da vida passa pela consciência e responsabilidade ao assumi-lo. 0 participante aponta que, para ele, o sentido da vida passa por uma mudança em relação à forma que vivia, pois hoje deseja ter responsabilidade e consciência de seus atos.

0 participante A expressa o mesmo desejo de mudança em relação à responsabilidade e consciência de seus atos, mas afirma que não conseguia por causa da facilidade de obter drogas nas ruas: sempre quando tu quer mudar, sempre tem algum pra te oferecer ou pra te aliciar, na rua não tem como mudar. Eu acho pra mim que na rua não tem como mudar. Na rua o bagulho é mais forte.

$\mathrm{O}$ participante $\mathrm{C}$ destaca que hoje ele se sente diferente em relação ao contato com a droga nas ruas: hoje em dia, na rua, eu já tô mais forte. Torna-se assim visível o desejo dessas pessoas em ter maior responsabilidade e conscientização de suas atitudes.

Família

Segundo Frankl (1990), o homem modesto e sincero é quem vivencia valores e sabe que o sentido da vida está ligado ao trabalho e ao amor. Os participantes destacaram a importância que hoje dão à família, associando a ela o que chamaram de resgate dos valores de honestidade e sinceridade.

0 participante A traz que deseja ser mais honesto, uma pessoa honesta, ser uma pessoa humilde, ser mais aberto pra família. $\mathrm{O}$ entrevistado $\mathrm{C}$ destacou que: ser honesto e sincero. De acordo com os valores vivenciais descritos por Frankl (1986), as pessoas se realizam pelo fato de acolherem algo do mundo, seja por meio da natureza ou da arte.

0 entrevistado $C$ relata o que busca, na sua relação com a filha, algo que não teve na relação com seu pai: Deixar um exemplo bom pra minha filha. Ser o pai que eu não tive, no caso ... dando amor e correndo atrás do tempo perdido ... preciso ter algo de bom para deixar para minha filha, pra passar pros outros.

$\mathrm{Na}$ fala de todos os entrevistados, foi enfatizado que hoje veem a importância da família. Destacam que a família é a base, a família é a base do cara. Esse posicionamento mostra que o sentido da vida para eles pode estar relacionado aos familiares, mostrando a eles a sua mudança de vida.
Futuro

Em relação ao futuro, destacam que hoje acreditam existir algo que somente eles podem cumprir, relacionado ao trabalho, recuperação e na relação familiar. 0 sentido da vida, apontado por Frankl (1991), consiste em acreditar que cada pessoa tem uma missão específica a realizar e precisa executar essa tarefa, não podendo ser substituída por outra pessoa.

0 participante $C$ fala da sua missão em relação a sua filha: eu acho que com a minha família, assim, com o meu dever de ser pai. Eu acredito que só eu possa, né, porque é minha filha. Em relação à família, como trouxe o participante, percebe-se que as atribuições de cada membro da família é uma tarefa realmente única, por isso, ele a destaca como insubstituível, que somente ele poderá exercer o dever paterno.

O participante B fala sobre seu trabalho como sendo ele o único que pode realizá-lo: tem coisas assim como o meu serviço, né? Tem muita gente que não sabe, né, mas eu, pelo menos, eu tem coisas que eu nunca mexi, mas eu vou, mexo e consigo arrumar.... Esse participante dedica-se ao trabalho e conhece suas potencialidades na função que exerce. Enfatiza a dedicação que tem em cumprir sua missão em relação ao trabalho prestado, pois vê sentido naquilo que faz.

A missão da vida, segundo os valores criadores, pode coincidir com o trabalho profissional, que, por sua vez, leva o sujeito a se relacionar com sua comunidade contribuindo para o meio em que está vivendo. Frankl (1986) faz a ressalva de que a profissão não é o suficiente para trazer a plenitude ao homem, nem tornar um sujeito feliz. Segundo o autor, a profissão ainda não é o suficiente para o homem tornar-se insubstituível; porém serve como uma oportunidade para o indivíduo poder vir a ser.

0 participante A fala sobre sua recuperação: ... acho que tudo envolve a minha recuperação, né? A minha recuperação, só eu posso realizar ela; não tem como a minha mãe, meu pai realizar por mim ela ... 0 entrevistado falou sobre sua vida e o empenho que tem dado em manter sua recuperação; não acreditando que isso seja função de outra pessoa, mas, sua, fazendo da recuperação o sentido da sua vida, no momento, ou seja, é algo intransferível à outra pessoa realizar para ele, pois, se esse desejo não partir dele, não tem como manter-se em recuperação.

$O$ entrevistado $C$ fala em relação ao que almeja do momento atual para o futuro: Eu busco, de agora 
daqui pra frente, fazer o bem. 0 mesmo participante ainda traz que pra mim, em particular, acho que sentido da vida a partir da hora do término da primeira parte do meu tratamento é primeiramente ficar sóbrio e fazer o bem, fazer o certo, passar algo de bom, assim, pras pessoas, assim.

Fé

Em relação à fé, todos os participantes relataram a importância, nesse momento de suas vidas, da crença em Deus. Todos os pontos, descritos pelos participantes, estão de acordo com Frankl (2007) quando diz que a fé faz parte de uma tendência inconsciente que o homem tem para acreditar na figura de Deus.

O fato antropológico da autotranscendência é algo primordial do ser humano, que busca sentido a realizar num outro que não seja ele próprio. A autotranscendência é de fato antropológica sempre quando se refere a algo, alguém ou alguma coisa que não seja ela, para ter um objetivo a ser alcançado ou a existência de outra pessoa que a encontre (Pereira, 2007).

O participante C fala: eu acho que eu tenho que confiar no meu poder superior, no meu Deus e fazer o bem pra receber o mesmo ... me apegar a Deus ... Essa tal questão, o participante mostra a necessidade em buscar por algo entendido como superior, como ele descreveu, de confiar em Deus; isso retrata a autotranscendência da existência humana saindo de si para encontrar forças num poder superior.

0 entrevistado continua relatando como era seu pensamento a respeito da fé eu fui aquele cara que passava na frente da igreja e zoava com o pessoal lá dentro, e tal, e tirava onda, achava que não existia, ou achava que todo mundo era louco e eu era o certo ... . Esse participante ainda destaca que é preciso ter o auxílio do seu "poder superior" para conseguir manter sua vida sem drogas fora da instituição: $d e$ pois que eu conheci um pouco da palavra, que eu vi que sem Deus eu não vou conseguir, lá fora eu não vou conseguir ... . De acordo com essas falas, observamos que a pessoa, descrita por Viktor Frankl como ser bio-psico e espiritual são condizentes com o que diz o entrevistado que antes tinha um posicionamento ateísta e hoje manifesta sua crença em Deus.

O ser humano, na logoterapia, apresenta a totalidade bio-psico-noética. A dimensão noética é vista por Frankl como superior, pois as dimensões somática e psicológica interagem no paralelismo psicofísico regido pela homeostase e passível de condicionamento. Já a dimensão espiritual, como é conhecida a dimensão noética, é incondicionável, não homeostática e interage com as demais de forma oposta ao paralelismo psicofísico (Frankl, 1986). Roehe (2005) complementa que ignorar a dimensão noética, ou simplesmente reduzi-la à dimensão psicológica, é ter um entendimento reducionista do homem.

Ao falar em dimensão espiritual, deve ficar esclarecido que Frankl não considera da mesma forma que as religiões descrevem, por isso a logoterapia não deve ser confundida com religião (Gomes, 1992).

0 participante B fala que ... se a gente não tiver Deus, hoje em dia, a gente não é nada, porque Deus te leva onde tu quiser, mas tu tem que crer nele. Tem que pegar e crer em Deus. 0 mesmo participante salienta que: ... tenho ido na igreja, escutado a palavra. A igreja é tudo pra mim, sempre tô na igreja; quando tô em casa a melhor coisa pra mim é ir na igreja. Sou feliz indo na igreja; estando com Deus, sou feliz.

De acordo com Moreira, Abreu e Oliveira (2006), essa autotranscendência no atributo ontológico revela anseio do homem encontrar o sentido da vida, ultrapassando os limites psíquicos e biológicos.

\section{Recuperação}

De fato, para se obter uma condição de recuperação, é preciso se ter a consciência sobre a vida e sobre a responsabilidade perante esse contínuo acompanhamento. Xausa (1986) afirma que existem obstáculos a serem enfrentados para se obter uma liberdade. Para a autora, essa liberdade não pode ser confundida com arbitrariedade e libertinagem. A espiritualidade, a liberdade e a responsabilidade constituem a dimensão noética do sujeito.

A recuperação é um dos alvos nessa nova trajetória dos jovens dependentes em tratamento, pois, para obterem uma vida distante das drogas, buscam uma nova vida, seja por meio de ajuda psicológica ou espiritual, como o participante C salienta: ... eu vou tentar um tratamento com psicólogo, assim, quando eu tiver tempo, final de semana, e me apegar a Deus.

Coelho e Mahfoud (2001) destacam que a responsabilidade não é algo de caráter moralista, no qual o indivíduo é obrigado a agir de acordo com as normas introjetadas. Tal responsabilidade relaciona-se com a capacidade de responder pela liberdade que $o$ 
homem conquistou e desfruta, ou se posicionar diante das circunstâncias presentes. A dimensão espiritual é a dimensão da vivência da liberdade e da responsabilidade, por isso ela não é determinada, mas determinante da existência.

0 participante $\mathrm{C}$ destaca que: o principal objetivo na minha vida é me manter sóbrio, aconteça o que acontecer; independente da situação é a sobriedade. Ainda salientou o seu propósito: tenho o meu objetivo, né, que é a sobriedade, sair e me libertar de todas as formas, de qualquer tipo de droga.

A logoterapia procura a conscientização do espiritual para trazer ao homem a consciência do seu ser - responsável e essa responsabilidade se dá perante o sentido (Frankl, 1986). 0 participante A fala do que é mais importante na sua vida: $O$ mais importante é a minha recuperação, me recuperar, ter uma vida digna, uma vida que era pra mim ter antes. Só que foi perdida e eu quero ter essa vida de novo, ter uma vida digna...

Em relação à recuperação, todos se mantêm convictos de que ela é permanente, e que demanda grande esforço para sua manutenção. Isso mostra que hoje todos os participantes desejam desenvolver alguma consciência que possa implicar em responsabilidade, que, por sua vez, possa ser visualizada nas suas ações.

\section{Considerações finais}

Este tema foi desenvolvido graças ao grande foco que a sociedade tem dado à questão das drogas. Estudar a questão que envolve o sentido da vida e dependentes químicos, apoiado num referencial humanista e existencial, pode trazer benefícios na compreensão, planejamento e operacionalização dos programas de tratamento e recuperação dessas pessoas. 0 sentido da vida aparece como parte essencial na busca por êxito do tratamento do dependente químico.

As falas dos participantes que se encontram em tratamento hoje carregam a busca por um sentido em suas vidas, atribuindo a questões como família, trabalho, fé e recuperação, esta função. Todos os entrevistados têm um planejamento para o futuro que passa pela manutenção da própria sobriedade e de uma colocação no mercado de trabalho. A necessidade em pertencer e estabelecer laços afetivos com o grupo familiar parece bem evidente durante todo o trabalho.
Identificou-se que os jovens dependentes químicos que se encontram em tratamento recorrem a um novo sentido para viver, buscando esse encontro a partir do momento que se conscientizaram que necessitavam de ajuda. Os entrevistados, hoje, procuram ver o mundo de outra forma, procuram um novo modo de pensar e agir.

Para a eficácia de qualquer tratamento envolvendo a dependência química, devem ser levadas em conta as questões do sentido da vida. 0 questionamento de verificar o sentido da vida deve partir do dependente químico, e, a partir daí, começar a descobrir uma nova forma de viver. Nem sempre esse questionamento, que pode ser comparado a uma tentativa de estabelecer a consciência e a responsabilidade, se torna possível. Nesse contexto, a logoterapia pode representar uma alternativa para a recuperação do dependente, associada aos programas de internação e desintoxicação já aplicados.

Os estudos envolvendo as questões existenciais ainda são pouco aplicados à questão das drogas. A necessidade de compreender o ser humano na perspectiva holística, levando em consideração sua constituição de um ser biopsicossocial e espiritual, torna-se necessária no processo de recuperação dos dependentes químicos. A busca pelo sentido foi evidenciada pelos resultados desse estudo, que vem a confirmar sua importância na existência humana, mesmo quando esta se encontra em condições desfavoráveis.

\section{Referências}

Aquino, T. A. A., Correia, A. P. M., Marques, A. L. C., Souza, C. G., Freitas, H. C. A., Araújo, I. F., et al. (2009). Atitude religiosa e sentido da vida: Um estudo correlacional. Psicologia Ciência e Profissão, 29(2), 228-243.

Bauer, M., \& Gaskell, G. (2005). Pesquisa qualitativa com texto, imagem e som: Um manual prático (4. ed., P. A. Guareschi, Trad.). Petrópolis: Vozes.

Carlini, E. A., Galduróz, J. C. F., Noto, A. R., \& Fonseca, A. M. (2004). V Levantamento Nacional sobre o consumo de drogas psicotrópicas entre estudantes do ensino fundamental e médio da rede pública de ensino nas 27 capitais brasileiras: 2004. São Paulo: CEBRID; UNIFESP; USP. 
Carlini, E. A., Silva, A. A. B., Noto, A. R., Fonseca, A. M., Carlini, C. M., Oliveira, L. G., et al. (2006). II Levantamento domiciliar sobre o uso de drogas psicotrópicas no Brasil: Estudo envolvendo as $\mathbf{1 0 8}$ maiores cidades do país: 2005. São Paulo: CEBRID; UNIFESP; USP.

Coelho, A. G. Jr., \& Mahfoud, M. (2001). As dimensões espiritual e religiosa da experiência humana: Distinções e inter-relações na obra de Viktor Frankl. Psicologia USP, 12(2), 95-103.

Déa, H. R. F., Santos, E. N., Itakura, E., \& Olic, T. B. (2004). A inserção do psicólogo no trabalho de prevenção ao abuso de álcool e outras drogas. Psicologia Ciência e Profissão, 24(1), 108-115.

DSM-IV-TR $^{\text {TM }}$ (2002). Manual diagnóstico e estatístico de transtornos mentais (4. ed., C. Dornelles, Trad.). Porto Alegre: Artmed.

Frankl, V. E. (1986). Psicoterapia e sentido da vida: Fundamentos da logoterapia e análise existencial (2. ed., A. M. Castro, Trad.). São Paulo: Quadrante.

Frankl, V. E. (1990). Psicoterapia para todos: Uma psicoterapia coletiva para contrapor-se à neurose coletiva (A. E. Allgayer, Trad.). Petrópolis: Vozes.

Frankl, V. E. (1991). Em busca de sentido: Um psicólogo no campo de concentração (7. ed., W. O. Schupp \& C. C. Alevine, Trad.). São Leopoldo: Sinodal; Petrópolis: Vozes.

Frankl, V. E. (2005). Um sentido para vida: Psicoterapia e humanismo (14. ed., V. H. S. Lapenta, Trad.). Aparecida: Ideias e Letras.

Frankl, V. E. (2007). A presença ignorada de Deus. (11. ed., W. O. Schlupp \& H. H. Reinhold, Trad.). São Leopoldo: Sinodal; Petrópolis: Vozes.

Gil, A. C. (2006). Métodos e técnicas de pesquisa social (5. ed.). São Paulo: Atlas.

Gomes, J. C. V. (1992). Logoterapia: A psicoterapia existencial humanista de Viktor Emil Frankl (2. ed.). São Paulo: Loyola.

Guimarães, C. F., Santos, D. V. V., Freitas, R. C., \& Araujo, R. B. (2008). Perfil do usuário de crack e fatores relacionados à criminalidade em unidade de internação para desintoxicação no Hospital Psiquiátrico São Pedro de Porto Alegre (RS). Revista de Psiquiatria do Rio Grande do Sul, 30(2), 101-108. doi:10.1590/ S0101-81082008000300005
Laville, C., \& Dionne, J. (1999). A construção do saber: Manual de metodologia da pesquisa em ciências humanas. Porto Alegre: Artmed.

Martins, J., \& Bicudo, M. A. V. (1994). A pesquisa qualitativa em psicologia: Fundamentos e recursos bási$\cos$ (2. ed.). São Paulo: Moraes.

Moreira, J. O., Abreu, A. K. C., \& Oliveira, M. C. (2006). Moralidade e sociabilidade em Frankl: Um norte para superação da violência. Psicologia em Estudo, 11(3), 627-635. doi:10.1590/S1413-73722006000300019

Nassif, A. C. N. F. Filho, Bettega, S. G., Lunedo, S., Maestri, J. E., \& Gortz, F. (1999). Repercussões otorrinolaringológicas do abuso de cocaína e/ou crack em dependentes de drogas. Revista da Associação Médica Brasileira, 45(3), 237-241. doi:10.1590/ S0104-42301999000300008

Pereira, I. S. (2007). A vontade de sentido na obra de Viktor Frankl. Psicologia USP, 18(1), 125-136.

Pereira, I. S. (2008). Mundo e sentido na obra de Viktor Frankl. PSICO, 39(2), 159-165.

Pratta, E. M. M., \& Santos, M. A. (2009). O processo saúde-doença e a dependência química: Interfaces e evolução. Psicologia: Teoria e Pesquisa, 25(2). Recuperado em 30 maio 2010, em http://www.bvs-psi.org.br/

Roehe, M. V. (2005). Revendo ideias de Viktor Frankl no centenário de seu nascimento. PSICO, 36(3), 311-314

Rodrigues, D. (2000). 0 adolescente hoje. Porto Alegre: Artes e Ofícios.

Scarparo, H. (Org.). (2000). Psicologia e pesquisa: Perspectivas metodológicas. Porto Alegre: Sulina.

Xausa, I. A. M. (1986). A Psicologia do sentido da vida. Petrópolis: Vozes. 